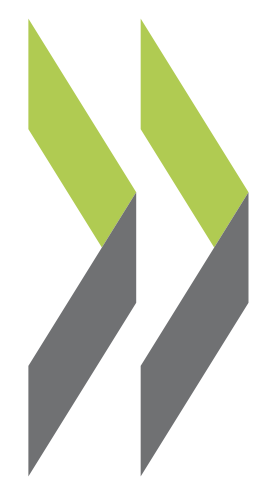

OECD Local Economic and Employment Development (LEED) Papers 2011/08

Framework and Tools for Assessing and Understanding Randall W. Eberts the Green Economy at the Local Level 


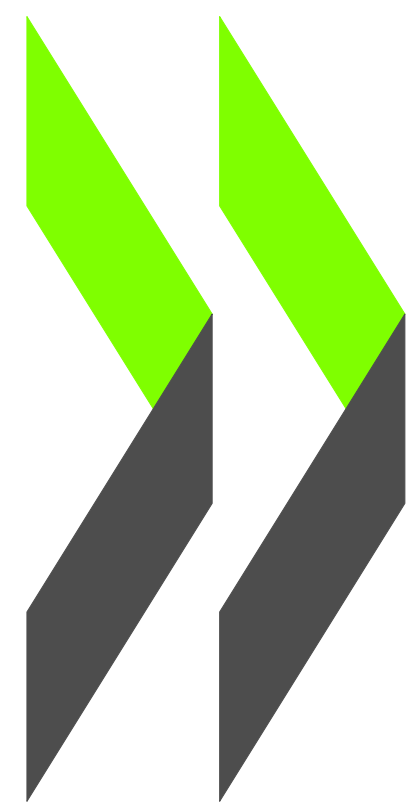

\section{FRAMEWORK AND TOOLS FOR ASSESSING AND UNDERSTANDING THE GREEN ECONOMY AT THE LOCAL LEVEL}

MAY 2011

Prof. Randall W. Eberts
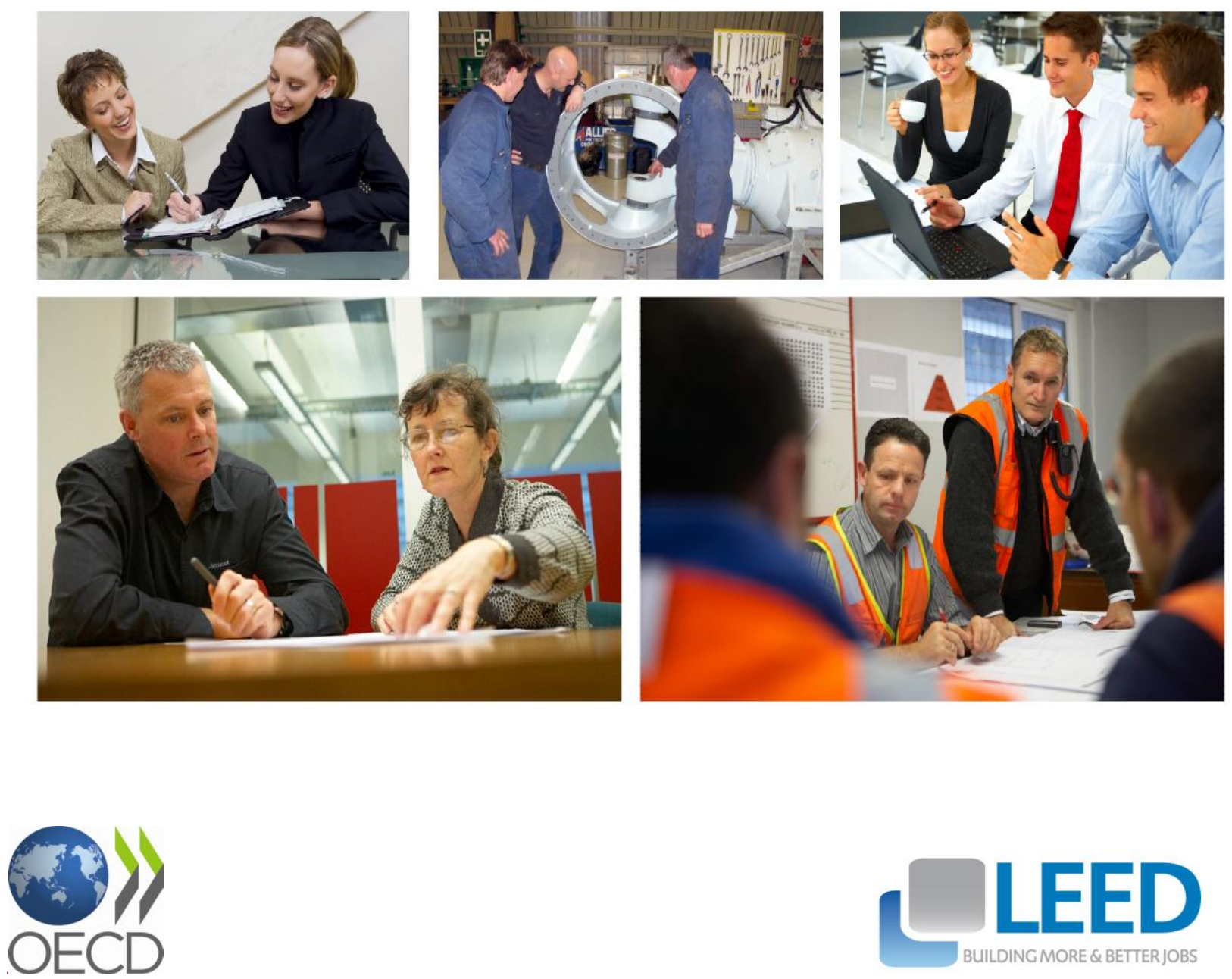


\section{FOREWORD}

The transition to a green economy will imply many changes in the labour market locally and the local development systems. The impacts are still difficult to measure as definitions vary and policy uncertainties persist. The OECD Local Economic and Employment Development (LEED) Programme is making an important contribution to these debates with its project on Climate Change, Employment and Local Development which is looking at the obstacles hindering green growth at the local level and the policy frameworks needed to ensure skills availability, economic activity and market opportunities in the green economy. Gabriela Miranda, from the OECD LEED Secretariat, leads this project and supervised the present report.

The content of this report was presented and discussed at a capacity building seminar on Local Strategies for Greening Jobs and Skills held at the OECD LEED Trento Centre for Local Development on 9-11 June 2010 as part of the OECD LEED Forum on Partnerships and Local Governance. This report feeds into the analysis of the OECD LEED project on Climate Change, Employment and Local Development, which itself contributes to the OECD Green Growth Strategy, a horizontal project involving several directorates.

I am very grateful to Prof. Randall W. Eberts and the W. E. Upjohn Institute for Employment Research Kalamazoo in the United States for this important contribution to the work of the OECD and its LEED Programme. I am confident that this valuable report will signify a useful tool for policy makers and local authorities willing to make the most out of this transition to a green economy in their localities.

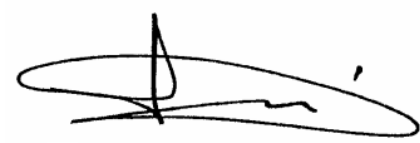

Sergio Arzeni 


\section{TABLE OF CONTENTS}

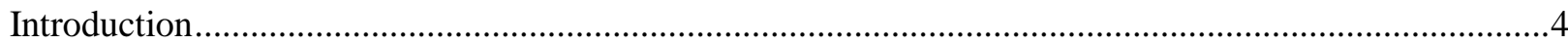

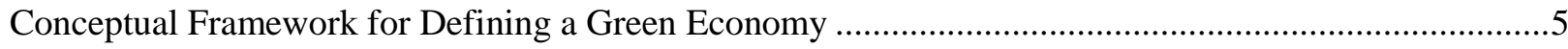

Estimating the Employment Effects of Greening the Economy …....................................................

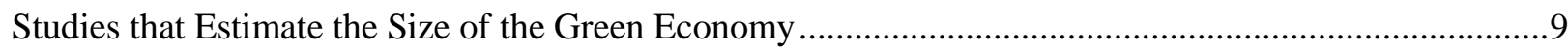

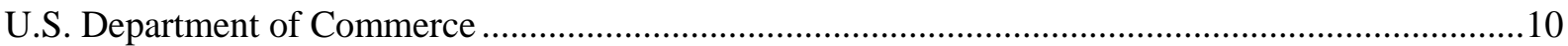

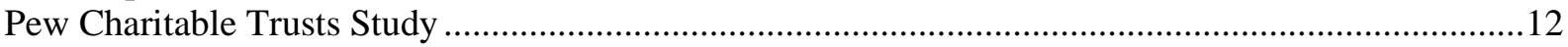

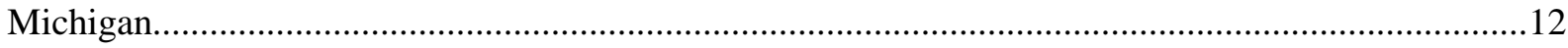

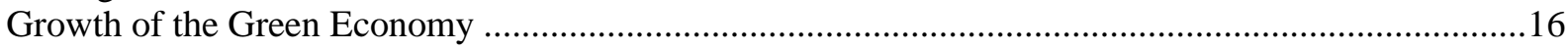

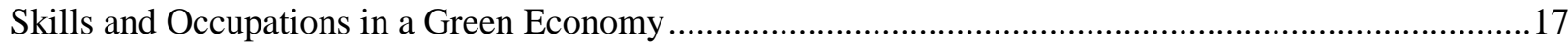

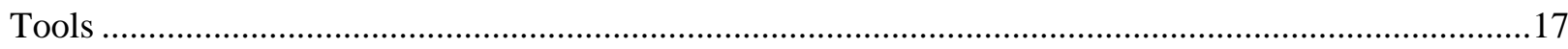

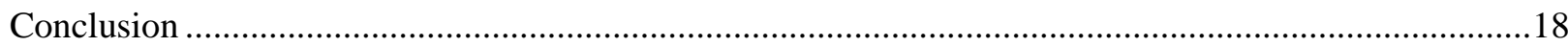




\section{Introduction}

Considerable attention is being given to the development of a green economy and the creation of "green jobs". At the global and national levels, this attention has been prompted by growing concerns about climate change and the projected inability of the world economies to sustain into the future the growth rates that they have enjoyed in the past without irreversible environmental consequences. Many countries are committed to fostering the development of a green economy, that is, a clean and energyefficient economy. Administrations of several countries see investing in a green economy as a way of helping their economies to recover. The OECD, for example, asserts that the "financial and economic crisis creates room for public policies aimed at encouraging recovery and renewed growth on more environmentally and socially sustainable grounds." Countries, such as the United States, included the development of new energy-saving technologies and other green activities as major components of their stimulus packages to help pull their economies out of the Great Recession. In the longer run, net oilconsuming countries perceive the emphasis on a green economy as a way of balancing trade accounts through reducing oil imports and thus reducing the flow of domestic wealth to other countries.

At the local level, states, territorial, and metropolitan areas see an opportunity to stimulate their economies by capitalizing on the green wave of innovation, and new product and service development. For example, the State of Michigan in the U.S. sees the new green economy as providing a "dynamic opportunity to rebuild the state's job base, attract new investment, and diversify the state's economy.", The State of Maine considers the greening of its economy as a "necessary progression and an opportunity for renewed economic growth by increasing business productivity, improving its energy efficiency and lowering the cost of heating and cooling its buildings." ${ }^{3}$ Similar strategies are being pursued in places in other countries.

Why the need to define a green economy and "green jobs"? The ILO warns that "the transformation will have profound impacts on the way we produce, consume and earn a living in all countries and sectors. ...It will be a second great transformation, on the scale of the industrial revolution." ${ }^{4}$ Furthermore, the ILO asserts that this transformation needs to occur quickly and comprehensively, involving millions of enterprises and workers who must contribute to drastically improving energy efficiency and shifting to clean sources of energy in order to avoid irreversible and dangerous climate change effects on economies and societies. These shifts will cause major structural changes in economies and labour markets. ${ }^{5}$

This raises a series of questions for businesses, workers, and policy makers at all levels internationally, nationally, and locally.

- What does a shift to a low-carbon economy mean for jobs and skills?

- In which sectors are jobs likely to be created and destroyed?

- Does moving to a low-carbon economy necessarily mean lower productivity, lower wages, and slower economic and job growth?

- Or is the green economy the next wave of growth and innovation that will stimulate growth at the local and national levels, raising overall standard of living?

- What are the skills and technology needed to accommodate growth in the green economy?

To begin to find answers to these questions, one must define a green economy and green jobs. Furthermore, recognizing that at present what might be considered green sectors and jobs make up only a 
small portion of the economy, it is also important to understand how the green economy relates to the rest of the economy and how it may evolve over time. First, identifying sectors of the economy that conserve energy and reduce pollution is important for understanding the extent to which the economy has started the transformation. And consequently, how much further it needs to go to mitigate and eventually reverse the adverse effects on the environment. Most studies show the green economy to comprise no more than 5\% of the entire national economy. For the U.S., the green economy's share is $1 \%$ to $2 \%{ }^{6}$ Therefore, its relatively small size suggests that the green economy is in a position to grow quickly but its small size also serves as a warning that the transformation is in its infancy and much more has to be done in order to avoid the dire consequences feared if the growth in carbon consumption is not abated.

However, defining a green economy is only the first step in understanding the benefits and consequences of pursuing low carbon and clean energy growth. The next step is to understand the market forces and impacts of government programmes and policies that can drive the economy toward those goals. Most experts contend that market forces alone, particularly because of the relative abundance of carbonbased energy sources now and into the near future, will not move the economy toward lower carbon emissions quickly enough to avoid environmental consequences related to greenhouse gases. ${ }^{7}$ Incentives such as carbon taxes and government-funded research and development and infrastructure investment are required. These incentives must be long term and of sufficient magnitude to affect consumer demand and production technologies. A developed economy is complex with its myriad interactions among consumers and producers, and the market forces that drive consumption and production decisions are not always easily understood as the countless combinations of transactions respond to price differentials and other incentives. Interactions between government policies to reduce carbon emissions can also be complex. ${ }^{8}$

While an analysis of market forces and policy effects is beyond the scope of this paper, the paper does offer a conceptual framework that provides a basis for recognizing the complex interactions between sectors when considering the economic effects of transforming an economy. Some studies, which attempt to define a green economy and estimate its size relative to the rest of the economy, may unintentionally leave the impression that identifying green industries and encouraging investment in them is enough to move the economy toward a greener future. Studies that identify green businesses and products may also tempt policy makers to target certain industries as growth potentials simply because they have been labelled as green. The potential for green activities to contribute to future growth is real, but simply because a sector is considered green today does not necessarily mean that it will be a growth sector into the future. Furthermore, most studies offer little insight into the importance of green sector activities in contributing to a greener economy.

The purpose of this paper is fivefold. First, it presents a simple framework that emphasizes the complex nature of a developed economy and how one needs to appreciate and understand the interactions among the various sectors in order to recognise the benefits and consequences of the transformation toward a low carbon and clean energy economy. Second, the paper offers an example of a study that takes into account the interactions of the various sectors in estimating the employment effects of moving toward a clean energy economy. Third, several studies using different methodologies are highlighted that provide estimates of the size of the green economy and its growth during this decade. Fourth, an example of addressing the skill needs of a green economy is described briefly. Finally, a list of tools that can be useful in addressing the questions listed above is provided.

\section{Conceptual Framework for Defining a Green Economy}

There is no one official definition of green industries or of "green jobs". Many organisations have developed their own definitions. Although the exact definition of green varies across organisations, there are more similarities than differences in what constitutes a green economy. ${ }^{9}$ A common theme is to conserve energy and other natural resources and reduce pollution. Most of the studies attempt to identify 
products and services that meet one of several criteria of a green economy. For products and services, most definitions include:

1. Environmentally friendly and enhancing products and services

2. Renewable energy products and services

3. Clean transportation and fuels

4. Green buildings

Some definitions also include the processes by which these products and services are produced. These include:

1. Energy efficient manufacturing, distribution, and construction

2. Reduction of energy, materials, and water consumption through high efficiency strategies

3. Switch from carbon to non-carbon components.

Figure 1. Conceptual Framework

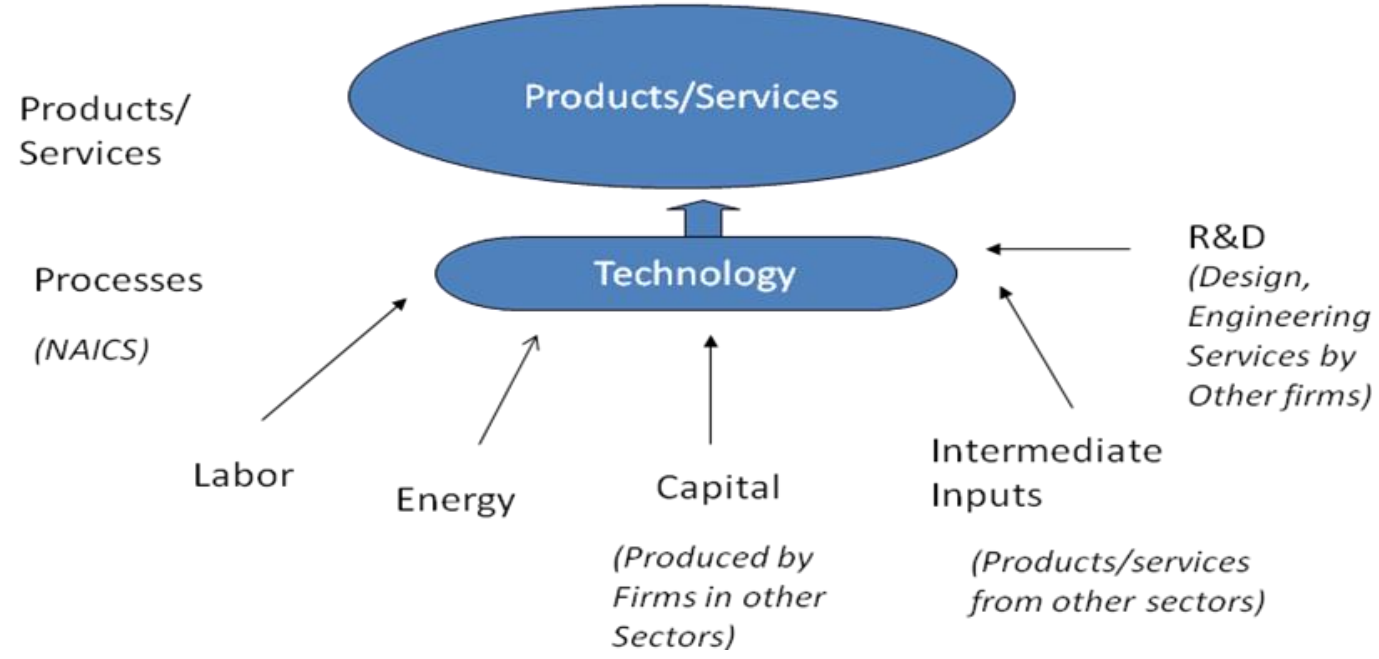

Source: Author

The conceptual framework, displayed in Figure 1 above, shows the relationship between products and services and the processes used to produce them. Businesses produce products and services by combining inputs such as labour, capital, energy, and intermediate products. These inputs are combined using specific technologies, which are developed through design and engineering services. These inputs are obtained to various extents from other organisations, constituting a business's supply chain. Energy is obtained from public utilities producing electricity or providing natural gas for manufacturing processes or to heat buildings. Capital, the equipment used to produce the products and the buildings used to house the production processes, is typically obtained from other firms in other sectors of the economy. Intermediate products, such as computer components or parts for automobiles, are most likely produced by other organisations and assembled at the final stage of production. Research and development (R\&D) can also be provided by other firms as well as be provided internally by the business producing the final product. While the description of the "production" process appears to be more germane to the products, it can also be applied to services. For all services and products, the relative amount of each input depends upon the 
particular product or service. Obviously, the production of an automobile is less labour intensive and more energy intensive than the provision of medical services within a hospital setting.

The bringing together of inputs to produce goods and services and then distributing the final output to consumers is the result of a complex array of interactions between numerous businesses and consumers. Recognizing the often complex relationship between products/services and the inputs required to produce them raises several issues with defining green economy. ${ }^{10}$ First, considering the function of an end-use product or service alone may not be sufficient in determining whether it contributes to criteria that describe a green economy. It is also important to consider the chain of products and processes that lead to the production of that final end-use product. A product may be considered green, but the inputs used to produce that product may or may not be green. These inputs could be sufficiently large as to negate the "green" aspect of the final product. Moreover, that green product (or service) could also be used in the production of a product (or service) that is not green. In that case, it is still conceivable that the use of a "green" input could offset the "non-green-ness" of the final product. For instance, hybrid automobiles are listed as a green product by many organisations. While the energy efficiency of driving a hybrid may be greater, one must also take into consideration the energy consumption and potential pollution of producing and eventually disposing of the battery that is central to a hybrid's power source. The same consideration needs to be given to the emerging fuel cell technology. Similar examples can be found when considering the environmental consequences of generating electricity using biomass or the potential hazardous waste issue surrounding nuclear power.

Second, since many inputs are produced by other businesses located in other places, one must also take transportation costs into consideration when identifying the products and services that constitute a green economy. The transportation of oil from distant parts of the globe to intensive-energy consuming countries is an obvious example of using energy to deliver energy, and illustrates the possible 1 dire environmental consequences when something goes awry.

Third, it is apparent from the conceptual framework that the variation across products and services in the use of inputs and the technologies available in transforming inputs into products and services determines to a large extent the potential for a product/service sector to contribute to the objective of reducing greenhouse gases and provide for a more sustainable economic growth path. However, considering each product or service separately, without understanding their linkages to other products/services, provides only a partial view, if any, of its contribution to promoting a greener economy. Even if one has determined that a particular sector comprises a significant share of a green economy, it is not possible to determine from that information alone whether it contributes proportionately to a cleaner economy. Furthermore, it is not possible to determine the potential contribution of its future growth on a greener economy. For instance, the U.S. Department of Commerce has estimated that services comprise $77 \%$ of the green portion of the U.S. economy, as measured either by shipments/receipts or employment. However, this information on the size of the service sector does not necessarily indicate that the service sector has the largest potential impact on the objectives of a green economy and thus should be targeted for future investment. Only by examining the energy consumption and other green criteria of the service sector can one assess the potential green benefits of that sector's future growth and the merits of targeting it for investment. 
Fourth, sectors designated as green do not necessarily contribute equally to a cleaner economy, such as conserving energy and reducing pollution. Furthermore, studies that define a green economy give us no clue as to their contribution to these goals, since they do not link the green-designated sectors to any information about energy conservation or other green economy characteristics. ${ }^{11}$ For example, one sector that is included in the U.S. Department of Commerce definition of a green economy is "tire servicing." The rationale is that activities that inflate and balance tires improve mileage and reduce energy use. It is known that increasing tire pressure will increase gas mileage. But how much does the tire-servicing sector actually contribute to better fuel efficiency? No attempt is made to understand the green economy's effect in moving the entire economy to one that is cleaner and more energy and resource efficient. ${ }^{12}$

Fifth, since most definitions are based on specific products or specific businesses, the designation of a green product is not distinct. Businesses may produce green products along side non-green products. Or as previously asserted, a business may produce products that are greener alongside products that are not as green, although few studies defining the green economy try to make that distinction. ${ }^{13}$ For example, an automobile manufacturer may produce hybrid cars on one assembly line and less fuel-efficient cars on an adjacent assembly line. One production line may be considered a green economy activity whereas the other may not.

The conceptual framework also offers insight into how changes in different inputs could affect output and in turn how reallocation of products and services could affect inputs, such as the demand for energy and for labour. For example, suppose that the production of a product primarily uses electricity as its energy source. Further suppose that a greater percentage of electric power sent to this plant is generated from wind power. The type of energy remains the same - electricity - so the plant does not have to alter its technology or capital to use it. However, wind power generation of electricity is more expensive than coal-fired generation. The price of electricity to the plant increases, which increases the cost of production. Without any other productivity-enhancing measures available to the plant management, the cost of the product produced must also increase. This price increase could lower demand, which in turn lowers the demand for labour. Adding more expensive but "green" wind-power generation to the electric grid changes relative prices, resulting in a reallocation of labour and the demand for products across sectors. Other scenarios are possible, of course. Another could be that the plant decides to adopt a technology that uses biomass, which promises to meet the same energy needs at the same price as current electric rates. But to use this new source of energy, the plant needs to invest in new capital and technology. That increases the demand for sectors that offer this new technology, increasing the labour demand in that sector producing the new equipment. Since the cost of energy is the same and assuming that the new capital investment in biomass would cost the same as replacing capital with the existing technology, there would be little effect on the demand for labour by the company changing to biomass as the energy source.

\section{Estimating the Employment Effects of Greening the Economy}

The conceptual framework outlined above highlights the need to understand the production relationships between inputs and outputs in defining the green economy and the effect of investment in the green economy on other sectors of the economy. A recent study by the U.S. Department of Energy illustrates how a framework similar to the one described in the previous section can be used to assess the impact of reducing carbon use on employment. In a report to the U.S. Congress, the Department of Energy assessed the effects of a transition to a clean energy economy on employment in the United States. The study estimated the impacts of a transformation of the U.S. economy to the use of hydrogen between 2020 and 2050. This study is included in this overview of measuring the green economy for several reasons. First, it addresses the issue that is at the core of the interest in a green economy-a more energy efficient, less carbon-dependent, and more sustainable economy - by projecting several likely scenarios with respect to carbon reduction and employment change. Second, from a methodological perspective, the study follows the conceptual framework outlined in this paper and uses an input-output approach to assess the 
impact of carbon use on the entire U.S. economy. Third, it also attempts to assess the worker displacement and the change in skill needs due to a transformation toward a low-carbon based economy.

Central to the methodology is the use of IMPLAN, which is an input-output model, based on the most recent input-output tables produced by the U.S. government. An input-output model represents the interdependencies between sectors of the economy. For industrial sectors it shows the input requirements of producing a unit of a particular product. Furthermore, it shows how the output of one industry is the input of another and thus illustrates how dependent each industry is on all others in the economy both as consumers and producers. As mentioned in a previous section, an input-output approach is critical for understanding the impact on the economy, as well as for understanding the value chain relationships of end-use green products.

The study considers two scenarios of implementation of a hydrogen-based economy. The first, more aggressive case, assumes the success of the President's goal of saving 11 million barrels of oil per day by 2040, as laid out in the administration's Hydrogen Fuel Initiative (HFI). ${ }^{14}$ The second, less aggressive scenario, follows the U.S. Department of Energy's analysis supporting its 2007 programme, which has a less ambitious goal. For example, under the HFI the penetration of the light-duty vehicle stock with hydrogen powered vehicles by 2050 is $96 \%$; for the less aggressive case, the penetration is $38 \%$.

The net effect on U.S. employment, according to the study, is a slight increase from 2005 to 2020, by $0.13 \%$ under the HFI scenario and by $0.04 \%$ under the less aggressive scenario. More dramatic and interesting is the economic restructuring brought about by the adoption of hydrogen-based energy. Growth of jobs in the production of hydrogen vehicles and other hydrogen-using equipment will be offset by job declines in traditional industries. In all, job gains total 252040 while job losses amount to 69200 . Under HFI, the net employment effect is 182840 , which is a $0.13 \%$ increase from the base period of 2005 . By 2050, job gains total 751060 (0.41\% of 2005 employment) and job losses are 76560 (0.04\% of 2005 employment).

Employment effects differ across regions, according to the study. The upper Midwest, even though it is the centre of automobile manufacturing, is projected to have a slight net increase in employment. Total automobile manufacturing jobs are not expected to be affected by the switch to hydrogen power, since overall labour productivity is expected to remain unchanged. However, the shift to hydrogen will promote employment gains as the region shifts from the import of gasoline from other states to the production of hydrogen within the region. Under the HFI scenario, job losses will be minimal at 4000 in 2050 scattered across 14 sectors. Jobs created will total 110000 and will be distributed across 41 sectors. The total net employment is 104000 , or $0.44 \%$ of the region's base-case employment in 2050 . Job creation in the region ends up being slightly higher than the nation's.

Other regions highlighted in the study are also expected to grow, but at different rates. All regions will gain some jobs, but the largest differences among regions are the different industries that contribute to job gains and losses. According to the study, Houston and California will gain the most from additional jobs in professional and technology services; the lower New England and upper Mid-Atlantic States will gain the most from the production and delivery of hydrogen; and the upper Midwest's modest gains are spread evenly across a wide range of industries. ${ }^{15}$

\section{Studies that estimate the size of the Green Economy}

In the past several years, there has been considerable interest in estimating the size of the green economy and monitoring and projecting its growth. Various country studies have been conducted, and within certain countries, particularly the U.S., studies have focused on state and local areas as well. Criteria for identifying green activities and methodologies for estimating the size of the green economy 
vary somewhat, yielding different estimates. This section presents three studies, which use similar approaches but which differ enough in their methodologies, to offer different estimates of the size of the green economy in the same country and region. Specifically, these studies estimate the size of the green economy in the U.S. and in the state of Michigan.

\section{U.S. Department of Commerce}

The U.S. Department of Commerce released a report in early 2010 that measures the green economy. Their approach is to identify and assess green products and services based on the administration's energy conservation and environmental goals. They define green products and services as those whose predominant function serves one or both of the following goals:

- Conserve Energy and Other Natural Resources, which includes products or services that conserve energy to reduce fossil fuel use and promote water, raw material, land, and species and ecosystem conservation; or

- Reduce Pollution, which includes products or services that provide clean energy or prevent, treat, reduce, control or measure environmental damage to air, water and soil. The remediation, abatement, removal, transportation, or storage of waste and contaminants also are considered to reduce pollution. ${ }^{16}$

The study used the 2007 Economic Census, which measures business activity based on responses from more than 4.7 million companies. Using the six-digit North American Industry Classification System (NAICS), businesses are classified primarily as manufacturing or services industries. The data are further disaggregated into individual eight-digit product/service codes. While the Economic Census is the broadest and most detailed measure of the private sector, it has limitations. First, it includes only the private sector. The government sector, which comprises nearly $13 \%$ of GDP, is not included. Second, product codes were not designed to identify the environmental impact of products or services, rendering it impossible to determine the extent to which a green product actually contributes to the goals of a green economy. Third, the study identified a product as green based on its usage, not the production process by which is was produced or the environmental consequences associated with its use or disposal. Fourth, the product codes do not differentiate among similar products produced using different techniques, some which may conserve energy and others that may not. ${ }^{17}$ Fifth, while the product codes were quite narrow in scope, some of the product codes identified as green included a share of non-green products and services. It was impossible to determine the share of green products within a product code.

The analysts who conducted the study categorised green products and services by five types of green activity:

1. Resource conservation (RC)

2. Environmental assessment (EA)

3. Energy conservation (EC)

4. Renewable/alternative energy (RE)

5. Pollution control (PC).

They used two criteria for selection. What they referred to as the narrow definition included only products and services for which the analysts assumed there was wide agreement regarding their classification as green. The broader measure included products and services in which their green status 
was more open to debate. Of the more than 22000 product and service codes in the 2007 Economic Census, the study identified 407 product and service codes as green under the narrow definition, and 732 codes under the broader criteria.

Once a product code was identified as green, the next step was to compute the employment related to that green product. The computation of employment was complicated by the lack of employment information at the detailed eight-digit product code level. The most detailed accounting of employment is at the six-digit NAICS level. To impute employment within green product codes, the analysts assumed that the green products' share of employment in each six-digit NAICS industry is the same as their share of shipments/receipts within that NAICS industry. Applying the share to the employment of the specific sixdigit NAICS industry yields the employment associated with the green products within that NAICS industry. Adding up the imputed employment levels of green products within all six-digit NAICS industries yields total employment in the green economy.

Table 1 displays the value of shipments/receipts and the level of employment for the U.S. green economy, as estimated by the Commerce study. The estimates are divided into four sectors: agriculture, construction, manufacturing and services. Under the narrow definition, the value of products designated as green accounts for $1.3 \%$ of the U.S. economy; under the broader definition the percentage increases to $1.8 \%$. The green economy's share of employment is $1.5 \%$ under the narrow definition and $2.0 \%$ under the broader definition. The service sector accounts for the largest share of the green economy, whereas the construction sector includes the largest concentration of green products and services (as much as $4.1 \%$ of employment under the broader definition).

Table 1. Size of the Green Economy by Industry Sector, 2007

\begin{tabular}{|c|c|c|c|c|}
\hline \multirow[t]{2}{*}{ Industry Sector } & \multicolumn{2}{|c|}{ Measure } & \multicolumn{2}{|c|}{$\begin{array}{l}\text { Share of Total } \\
\text { Industry Sector }\end{array}$} \\
\hline & Narrow & Broad & Narrow & Broad \\
\hline \multicolumn{5}{|l|}{ Agriculture } \\
\hline Shipments/receipts (USD $\$$ billions) & 2 & 2 & 0.5 & 0.5 \\
\hline Employment (thousands) & 4 & 4 & 0.3 & 0.3 \\
\hline \multicolumn{5}{|l|}{ Construction } \\
\hline Shipments & 36 & 49 & 2.0 & 2.8 \\
\hline Employment & 224 & 304 & 3.0 & 4.1 \\
\hline \multicolumn{5}{|l|}{ Manufacturing } \\
\hline Shipments & 48 & 69 & 0.9 & 1.3 \\
\hline Employment & 197 & 241 & 1.5 & 1.8 \\
\hline \multicolumn{5}{|l|}{ Services } \\
\hline Shipments & 286 & 397 & 1.3 & 1.8 \\
\hline Employment & 1396 & 1833 & 1.5 & 1.9 \\
\hline \multicolumn{5}{|l|}{ All Sectors } \\
\hline Shipments & 371 & 516 & 1.3 & 1.8 \\
\hline Employment & 1821 & 2382 & 1.5 & 2.0 \\
\hline
\end{tabular}

Source: U.S Department of Commerce, "Measuring the Green Economy," April 2010, p. 12.

It is apparent from looking at the relative shares of shipments and employment that the share of shipments/receipts per worker is lower in the green economy than in the rest of the economy. If worker 
pay is related to shipment per worker, green workers receive less than non-green workers. The study shows that for services, the green worker pay is between 85 and $90 \%$ of non-green worker pay; whereas manufacturing worker pay is about the same between the green and non-green sectors.

\section{Pew Charitable Trusts Study}

Another study that estimates the size of the green economy in the U.S., both in terms of shipments/receipts and employment, was commissioned by the Pew Charitable Trusts. Pew developed the following definition of a green economy, referred to in their study as a clean energy economy.

According to the study, a clean energy economy generates jobs, business and investments while expanding clean energy production, increasing energy efficiency, reducing greenhouse emissions, waste and pollution, and conserving water and other natural resources. The clean economy cuts across five categories:

\section{Clean energy}

\section{Energy efficiency}

3. Environmentally friendly production

4. Conservation and pollution mitigation

5. Training and support ${ }^{18}$

This study followed a procedure of defining the green economy that was similar to the methodology used by the U.S. Department of Commerce, with one exception. Instead of using individual products and services as the unit of collection, it used individual businesses as the unit of observation. It took a conservative approach by counting only companies that could be verified online as being actively engaged in the clean energy economy. However, using businesses instead of products may over estimate the size of the green economy if businesses produce a mix of green and non-green products and services. The bias may go the other way if products recorded in the eight-digit product codes are broader than the products that businesses produce, and the mix of green and non-products in any given product code is greater than within a business. Another difference was that the Pew Study, by using individual businesses as the basis of their estimates, was able to provide estimates of the green economy for each state. One important similarity between the two studies was the focus on the supply of products and services generated by the green economy, not the businesses using these products to make themselves greener.

Based on this methodology, the Pew study estimated that the green economy accounts for $0.5 \%$ of the U.S. economy in 2007, or about 770000 jobs. This estimate is slightly less than half the size that the U.S. Department of Commerce estimated, even using their narrow definition. Many factors could account for the differences in the two estimates: definition of green, the selection of the green products or businesses, the difference between the product and business as the unit of observation. Pew contends that because their analysis focuses on identifying businesses in the clean energy economy and the jobs associated with these specific firms, its count of green jobs is conservative. ${ }^{19}$ Yet, regardless of the reasons, the size of the green economy derived from each study is small.

\section{Michigan}

The Michigan Department of Energy, Labour and Economic Growth prepared a report that estimates the occupations and employment in the green economy within its state. Other states have prepared their own estimates of their state's green economy, but the Michigan study is worth considering because of its 
methodology. Unlike the previous two studies, Michigan directly surveyed employers to see who is engaged in green economy activities. The survey was also instrumental in identifying the share of jobs in detailed industries that are related to the green economy. In addition, the survey questions were designed to allow employers to classify their green workers by core green activity, and collected information regarding employer expectations of future employment levels, difficulty in hiring qualified workers, green occupations requiring unique skills, and employee training. ${ }^{20}$

The report defines the Michigan green economy as industries that provide products or services related to five core green activities:

1. Producing renewable energy

2. Increasing energy efficiency

3. Clean transportation and fuels

4. Agriculture and natural resource conservation

5. Pollution prevention and environmental cleanup

The survey asked employers to identify jobs that produce goods or services related to these five activities. The survey instrument included examples of green activities for each of the five categories.

Based on the surveys, the study identified 96,767 direct green jobs and 12,300 support green jobs in Michigan. The direct green jobs account for $3 \%$ of the total private jobs and direct and support green jobs combined account for $3.3 \%$ of total private employment. ${ }^{21}$ Not surprisingly since Michigan's economy is highly dependent upon the transportation industry the core area of clean transportation and fuels comprised the largest share of total direct green jobs, as shown in Table 2. Table 3 shows that transportation equipment manufacturing has the most direct green jobs and is one of the industries with the largest concentration of green jobs (14.6\%).

Table 2. Number of Direct Green Jobs by Core Area in the Michigan Economy, 2006

\begin{tabular}{|l|l|l|}
\hline Core Area & Total Direct Jobs & Share of Total Direct Green Jobs \\
\hline Total Direct Green Jobs & 96767 & $100 \%$ \\
\hline Clean Transportation and Fuels & 39317 & 40.6 \\
\hline Increasing Energy Efficiency & 22236 & 23.0 \\
\hline Pollution Prevention and Environmental Cleanup & 12345 & 12.8 \\
\hline Agriculture and Natural Resource Conservation & 11986 & 12.4 \\
\hline Renewable Energy Production & 8843 & 9.1 \\
\hline Green Jobs not assigned to a core area & 2040 & 2.1 \\
\hline Total private employment & 3227600 & $3 \%$ of total employment \\
\hline
\end{tabular}

Source: Michigan Green Jobs Report, 2009, p. 13. 
Table 3. Top Michigan Industries Generating the Largest Number of Direct Green Jobs

\begin{tabular}{|c|c|c|c|c|}
\hline NAICS & Industry & $\begin{array}{l}\text { Total Direct } \\
\text { Green Jobs }\end{array}$ & $\begin{array}{l}\text { Total Industry } \\
\text { Employment }\end{array}$ & $\begin{array}{c}\text { Green Jobs \% of Industry } \\
\text { Employment }\end{array}$ \\
\hline 336 & Transportation Equipment Mfg & 25780 & 176254 & $14.6 \%$ \\
\hline 541 & $\begin{array}{l}\text { Professional, Scientific, and } \\
\text { Technical Services }\end{array}$ & 22178 & 241786 & 9.2 \\
\hline 238 & Specialty Trade Contractors & 9825 & 102467 & 9.6 \\
\hline 236 & Construction of Buildings & 3571 & 34423 & 10.4 \\
\hline 111 & Crop Production & 3503 & 15942 & 22.0 \\
\hline 562 & $\begin{array}{l}\text { Waste Management and } \\
\text { Remediation Services }\end{array}$ & 2168 & 11410 & 19.0 \\
\hline
\end{tabular}

Source: Michigan Green Jobs Report, 2009, p. 16. 
Table 4. Relation of Transportation Equipment Manufacturing to other Michigan Industries

\begin{tabular}{|c|c|c|}
\hline Motor vehicle bodies, trailers, and parts & 110011 & $59.1 \%$ \\
\hline Wholesale trade & 13978.8 & $7.5 \%$ \\
\hline Management of companies and enterprises & 8075.6 & $4.3 \%$ \\
\hline Plastics and rubber products & 8014.2 & $4.3 \%$ \\
\hline Turbine and power transmission equipment & 7389.3 & $4.0 \%$ \\
\hline Other fabricated metal products & 5471.3 & $2.9 \%$ \\
\hline Semiconductors and electronic components & 4091.2 & $2.2 \%$ \\
\hline Non-metallic mineral products & 3593.8 & $1.9 \%$ \\
\hline Electronic instruments & 2600.6 & $1.4 \%$ \\
\hline Audio, video, and communications equipment & 2492.8 & $1.3 \%$ \\
\hline Non-comparable imports & 2335.5 & $1.3 \%$ \\
\hline Truck transportation & 2171.7 & $1.2 \%$ \\
\hline Non-apparel textile products & 1843.4 & $1.0 \%$ \\
\hline Paints, coatings, and adhesives & 1553.7 & $0.8 \%$ \\
\hline Computer and peripheral equipment & 924.9 & $0.5 \%$ \\
\hline Leather and allied products & 919.1 & $0.5 \%$ \\
\hline Converted paper products & 898.4 & $0.5 \%$ \\
\hline Other general purpose machinery & 807.4 & $0.4 \%$ \\
\hline HVAC and commercial refrigeration equipment & 638.2 & $0.3 \%$ \\
\hline Other miscellaneous manufactured products & 606.7 & $0.3 \%$ \\
\hline Scientific research and development services & 601.3 & $0.3 \%$ \\
\hline
\end{tabular}

Source: Bureau of Economy Analysis, Input-Output Tables, 2002.

Table 4 shows how the auto industry is linked to many other industries. These industries may or may not be green. In fact the last sector listed in the table - scientific research and development services-is the sector with the second largest number of green jobs in Michigan. Since each industry provides inputs into the manufacturing of transportation equipment, the entire impact of the transportation equipment industry on the green economy goes beyond the concentration of green jobs in that industry (14.6\%). Growth in the transportation equipment sector induces growth in all the sectors listed in the table above. Knowing the concentration of green jobs in each sector would provide a better understanding of the impact of the transportation sector on Michigan's green jobs. ${ }^{22}$

The Michigan study also provides estimates of green jobs by occupational title, as reported by employers on the survey. As displayed in Table 5, the dominance of the transportation equipment industry 
leads to the proportionately large share of industrial engineers. These are considered green jobs since they improve efficiency and energy conservation through their design of more fuel efficient vehicles, and other conservation measures. Between 2006 and 2016, industrial engineers are projected to grow at a higher rate than any of the other green job occupations. The rate is $18.8 \%$ over that 10 -year period. Industrial engineers are in the category of higher educational attainment. In fact, the Michigan study shows that those occupations requiring higher educational attainment are expected to growth the fastest and also offer the highest compensation.

Table 5. Green-related Occupations with Expected High Growth Rate

\begin{tabular}{|c|c|c|c|c|c|c|}
\hline \multirow[b]{2}{*}{ soc } & \multirow[b]{2}{*}{ Occupational Title } & \multicolumn{2}{|c|}{ Employment } & \multicolumn{2}{|l|}{ Change } & \multirow[b]{2}{*}{ Education } \\
\hline & & 2006 & 2016 & Number & $\%$ & \\
\hline $17-2112$ & Industrial Engineers & 22290 & 26480 & 4190 & 18.8 & Higher \\
\hline $17-1022$ & Surveyors & 1230 & 1450 & 220 & 18.3 & Higher \\
\hline $37-3011$ & Landscaping workers & 33380 & 38160 & 4780 & 14.3 & Low \\
\hline $17-2081$ & Environment Engineers & 1860 & 2100 & 240 & 13.2 & Higher \\
\hline $17-1011$ & Architects & 2860 & 3220 & 360 & 12.5 & Higher \\
\hline $17-1012$ & Landscape Architects & 690 & 770 & 80 & 11.7 & Higher \\
\hline $17-2051$ & Civil Engineers & 6190 & 6870 & 680 & 11.0 & Higher \\
\hline $17-2041$ & Chemical Engineers & 1050 & 1160 & 110 & 10.5 & Higher \\
\hline $49-9041$ & Industry Machinery Mechanics & 10200 & 11170 & 970 & 9.5 & Moderate \\
\hline $11-9121$ & Natural Sciences Managers & 460 & 510 & 50 & 9.5 & Moderate \\
\hline
\end{tabular}

Source: Michigan Green Jobs Report, 2009, p. 49.

\section{Growth of the Green Economy}

One reason for defining a green economy is to assess how rapidly an economy is transitioning to a more sustainable economic path, assuming that the products services and businesses that have been identified by these studies reflect the objectives of a green economy. Each of the three studies provides historical trends as well as projections, based on their methodology, but each yields different estimates of green employment growth. The Commerce report compared product codes for manufacturing between the 2002 and 2007 Economic Census. Service sector codes were not comparable between the two years. For manufacturing between 2002 and 2007, the study found that green employment declined by 13000 under the narrow definition and fell by 12000 under the broad definition. Overall manufacturing employment declined as well during that period, leaving the share of green manufacturing the same.

The Pew study also showed a decrease in green employment between 2002 and 2007, but for all private sector green employees, not just those in manufacturing. Total green employment dropped by 
13218 , or $1.7 \%$, while total private employment during that same period increased $6.1 \%$. The Pew study also showed a slight decrease in green employment for Michigan, from 23238 in 2002 to 22674 in 2007. On the other hand, the Michigan study, using a survey approach, estimated an increase of 2517 greenrelated jobs between 2005 and 2007.

\section{Skills and Occupations in a Green Economy}

Transformation to a greener economy will undoubtedly result in the growth of some occupations and the decline of others. Along with this restructuring will be new occupations in the future with skill requirements that are not anticipated today. In order to begin to anticipate the demand for skills in the green economy, it is important to find ways to assess the skill needs and to understand career progressions to meet those demands.

Simply put, there are two types of changes in worker skills brought about by the green economy. The first is the increased demand for occupations with skills that are already associated with that occupation. In this case, an increase in green economy activities and technologies are likely to increase the employment demand for that occupation but will not lead to significant changes in the work or worker requirement. For example, more chemical technicians may be needed to conduct chemical and physical laboratory tests to assist scientists in making qualitative and quantitative assessments of the environment, but the skill sets required for future demand are similar to those today.

The second type of change in worker skills is that associated with a new and emerging occupation. The impact of green economy activities and technologies is sufficient to create the need for unique work and worker requirements, which results in a generation of new occupations. An example for this case is nanotechnology engineering technologist, who implements production processes for nanoscale designs to produce and modify materials, devices, and systems of unique molecular or macromolecular composition. Of course, there are other new and emerging occupations that may be prevalent tomorrow but have not yet been defined today.

The Michigan study offers an example of assessing the occupational demand and skill needs associated with growth in the green economy. That study relied on survey responses from businesses to assess the skill needs and the projected growth in occupations. Some of the results are described in the previous section. The Michigan study also drilled deeper into the requirements of green occupations and the career progression associated with occupations. To do that, they combined the survey results with $\mathrm{O} *$ Net, which is an assessment, primarily derived from survey responses, of the critical skills, knowledge, and aptitudes required for a wide range occupations. $\mathrm{O}^{*} \mathrm{Net}$ records these attributes for existing occupations, so future occupations per se are not covered, even though undoubtedly certain but perhaps not all aspects of current occupations may be transferable to future undefined occupations. By using $\mathrm{O}^{*} \mathrm{Net}$, which is a national database sponsored by the U.S. Department of Labour, a more detailed understanding of the requirements of green jobs can be assessed, and curriculum for training institutions and career progressions for workers can be developed.

As another example, the Environmental Defense Fund produced a Green Jobs Guidebook for California, which is intended as a resource for job seekers, students, guidance counsellors, career advisors, and policy makers. It includes job descriptions, salary information, education requirements, potential certifications, employer types, and job market growth potential, among other information. ${ }^{23}$

\section{Tools}

Not every entity can conduct an analysis of their green economy using the survey approach that Michigan followed. Surveys are expensive and time consuming on everyone's part. Michigan did 
demonstrate, however, that the information gleaned from a survey is quite valuable in accounting for green activities and green jobs, perhaps better than other approaches. Certainly the estimates of green jobs are much higher using the survey technique compared with the other approaches using standard data sources and "expert" (not employer) opinion of whether green activities are taking place in narrow product codes or at each business.

Yet, as the Michigan study demonstrated, surveys do not provide all the information needed to assess skill requirements for green jobs, nor do they offer insight into the relationships between the various sectors of the economy. Other data sources are required. Michigan combined survey results with a national database of skill requirements by occupation; the Hydrogen Economy study used a standard input-output programme (IMPLAN) to assess the interactions among industrial sectors.

Standard data sets and tools can be compiled to approximate and augment information obtained through surveys and other sources. These tools include:

1. National input-output tables to show the linkages among industries and the impact up the value chain of greater demand in any final-use sector.

2. Local input-output multipliers to estimate how much a one-time or sustained increase in economic activity in a particular region will be supplied by industries located in the region.

3. Industry-employment tables to estimate employment of each industry

4. Industry-occupation tables to identify the occupations employed by each industry

5. Occupation-skills tables to estimate the set of skills required by each occupation (e.g. O*Net).

One can see from this list of tools how the tools can be used to start with a specific product or sector of the economy, use the input-output table to relate that sector to others, relate the product sector to employment in that sector (through the industry-employment matrix), use the industry-occupation matrix to describe occupations associated with that product/sector, and then relate the occupation to skills. Local input-output multipliers can be used to focus on local impacts of green economy activities.

\section{Conclusion}

The response of government policy and market forces to climate change concerns present opportunities and challenges for nations and localities. Effective local green strategies require the ability to define and measure green jobs and products/services, to identify factors that will affect their size and growth, and to quantify their impact on the rest of the economy. This paper offers a conceptual framework to help understand the complexities of the relationship between green economy activities and the rest of the economy. Examples of studies that consider these issues are described in the paper, and tools are suggested that can help policy makers and others better understand the impact of a transformation to a greener economy on their regions and on those businesses and workers who reside there. 


\section{ENDNOTES}

1 OECD, May 2010

2 Michigan Green Jobs Report, 2009.

3 Maine's Green Economy, 2010.

4 The Green Jobs Programme of the ILO

5 The Green Jobs Programme of the ILO

6 U.S. Department of Commerce, Economics and Statistics Administration, "Measuring the Green Economy," April 2010, p. 11.

${ }^{7}$ Charles Goldman, et.al "Energy Efficiency Service Sector: Workforce Education and Training Needs," Ernest Orlando Lawrence Berkeley National Laboratory, March 2010, states that "for the past 30 years, public policy has been the key drive of energy efficiency investment in the United States” (p. 2).

${ }^{8}$ See Robert Stavins, Judson Jaffe, and Todd Schatzk, "Too Good to be True? An Examination of Three Economic Assessments of California Climate Change Policy”, NBER Working Paper 13587, November 2007.

9 The U.S. Department of Commerce's report "Measuring the Green Economy" provides a useful synopsis of various studies that define a green economy.

10 The OECD's “Interim Report on the Green Growth Strategy: Implementing our Commitment to a Sustainable Future," (OECD, May 2010)" recognises the importance of understanding the determinants of green growth and of related trade-offs or synergies in developing and implementing conditions that promote green growth. The report outlines a framework for a set of indicators that the OECD is developing to capture major aspects of green growth. According to the report, "the focus is on the environmental performance of production and consumption, and on drivers of green growth" (p. 47).

${ }^{11}$ OECD's "Interim Report of the Green Growth Strategy: Implementing our Commitment to a Sustainable Future," (OECD, May 2010) makes this same point that "it is important to measure whether green growth actually delivers reduced pressure on the environment and whether the environment is improving as a result" (p.46). The report suggests a framework for measuring the contribution of the green economy to reducing carbon emissions and other factors that is similar to the approach proposed here. It uses a growth accounting framework that relates inputs to outputs. Unlike the approach here, it includes a household consumption component.

${ }^{12}$ As discussed later, studies have estimated the relative contributions of different end-use sectors in moving toward the goal of reducing carbon emissions. See for example, Kyle, et al, "The Value of End-Use Energy Efficiency in Mitigation of U.S. Carbon Emissions, Pacific Northwest National Laboratory, Nov. 2007.

13 What I mean by shades of green is the contribution of a product or service to reducing carbon emissions or other aspects of a green economy.

14 The President's HFI consists of a USD 1.2 billion program to develop commercially viable hydrogen fuel cell and infrastructure technologies by the year 2020 . 
15 “Hydrogen Economy," p. 50.

16 The description of the two goals are taken verbatim from the report, "Measuring the Green Economy," U.S. Department of Commerce, April 2010, pp. 5-6.

17 The study did include product codes that were labelled "recycled," "rebuilt," "reused," or "reconditioned," with the understanding that these products conserved energy or reduced disposal waste by using all or a portion of existing material.

18 The Pew Charitable Trusts, "The Clean Economy: Repowering Jobs, Businesses and Investments across America," 2009 , p. 5.

19 Pew, p. 46.

20 Michigan Green Jobs Report 2009, p. 11. The sample size of the survey was 13,132 drawn from a population of 121,279 establishments in Michigan. The response rate was $49 \%$.

21 The Pew study estimated only 22,674 green jobs in 2007, compared to Michigan's estimate of 97,767 direct green jobs in 2009.

22 Obviously, measuring the impact of the transportation sector on the Michigan's green jobs, as described above requires that demand from all other sectors be held constant, so as not to double count. The economy is dynamic and demand across all sectors occurs simultaneously and this in turn induces demand throughout all the sectors, depending upon how closely they are linked to other sectors.

${ }^{23}$ Environment Defense Fund, “Green Jobs Guidebook” (www.edf.org/CAGREENJOBS). 


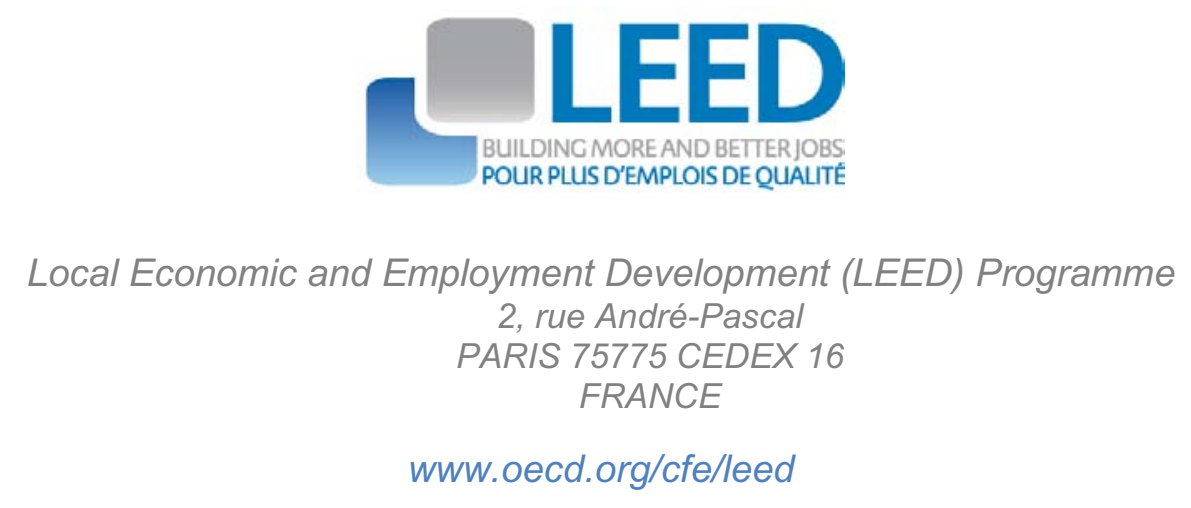

